\title{
An improved bottomside for the ionospheric electron density model NeQuick
}

\author{
Reinhart Leitinger $\left({ }^{1}\right)$, Man-Lian Zhang $\left({ }^{2}\right)$ and Sandro M. Radicella $\left({ }^{3}\right)$ \\ ( $\left.{ }^{1}\right)$ Institut für Physik, Institutsbereich für Geophysik, Astrophysik und Meteorologie (IGAM), \\ Universität Graz, Austria \\ $\left(^{2}\right)$ Laboratory for Space Weather, Center for Space Science and Applied Research, \\ Chinese Academy of Sciences, Beijing, People's Republic of China \\ $\left({ }^{3}\right)$ The Abdus Salam International Centre for Theoretical Physics (ICTP), Trieste, Italy
}

\begin{abstract}
The ionospheric electron density model NeQuick is a «profiler» which uses the peaks of the $E$-layer, the $F 1$-layer and the F2-layer as anchor points. In the version prepared for and submitted to the International Telecommunication Union (ITU) the model uses the ITU-R (CCIR) maps for $f o F 2$ and $M(3000) F 2$ and adapted maps similar to the ITU-R ones for $f o E$ and $f o F 1$. Since users found problematic behaviour of NeQuick under conditions of strong differences of $f o E$ and $f o F 2$ map structures, the profiling was adapted by changing the properties of the Epstein layers used for this purpose. The new formulation avoids both strange horizontal structures of the geographic distribution of electron density in fixed heights and unrealistic peculiarities of the height profile which occasionally occurred with the old version of the model. Since the Epstein layer approach allows for 8 parameters only (3 layer amplitudes and 5 semi-thicknesses) the adaptation was no minor task but needed careful planning of suitable strategies.
\end{abstract}

Key words ionosphere - electron density models profilers

\section{Introduction: the NeQuick formulation}

The purpose of this paper is to present the reasons for the revision of the bottomside of the three dimensional and time dependent electron density model NeQuick (Radicella and Leitinger, 2001) and to show some of the improvements gained by the revision.

NeQuick was submitted to ITU-R by the European Space Agency and was accepted by the relevant ITU-R authorities in July 2000. Source code, executable and two driver pro-

Mailing address: Dr. Reinhart Leitinger, Institut für Physik, Institutsbereich für Geophysik, Astrophysik und Meteorologie (IGAM), Universität Graz, Universitaetsplatz 5, A8010 Graz, Austria; e-mail: reinhart.leitinger@uni-graz.at grams are now available on the ITU-R web page <http://www.itu.int/ITU-R/software/studygroups/rsg3/databanks/ionosph>.

NeQuick-ITUR strictly follows relevant ITU-R recommendations and uses the ITU-R relation between average sunspot number $\left(R_{12}\right)$ and $10.7 \mathrm{~cm}$ solar radio flux $\left(F_{10.7}\right)$

$F_{10.7}=63.7+\left(0.728+0.00089 R_{12}\right) R_{12}$

or

$R_{12}=\left[167273+\left(F_{10.7-63.7}\right) 1123.6\right]^{0.5}+$ $-408.99$

with saturation of the $F 2$ layer critical frequency foF 2 and the transfer parameter $M(3000) F 2$ at $R_{12}=150$ (Recommendation ITU-R P.1239, ITU-R, 1997).

The model is formulated in the FORTRAN 77 language, uses a modular design and contains no COMMON blocks.

NeQuick is a «profiler» model which uses the peaks of the E-layer, the F1-layer and the 
F2-layer as anchor points. At any location the anchor points are derived from «maps» for the ionosonde parameters foE, foF 1, foF 2 and $M(3000) F 2$. The $f o F 2$ and $M(3000) F 2$ maps are from ITU-R (CCIR), the $f_{o} E$ map is a modified formulation of that due to John Titheridge (see Leitinger et al., 1995, 1996) and foF1 is taken to be $1.4 \times f o E$ (Leitinger et al., 1999) during daytime and is set zero during nighttime.

The maps are formulated in «modified dip latitude» $\mu: \tan \mu=I / \sqrt{\cos \varphi}$ where $\mu$ is (Rawer's) modified dip latitude or «MODIP» (Rawer, 1963); $I$, the magnetic dip; and $\varphi$, the geographic latitude.

The peak of the $E$-layer has a fixed height of $120 \mathrm{~km}$, the $F 2$ peak is constructed from $f o F 2$ (symbol $f_{F 2}$ ), $\mathrm{M}(3000) F 2$ (symbol $M_{3}$ ) and $f_{o} E$ (symbol $f_{E}$ ) using Dudeney's form of the Bradley and Dudeney (1973) formula (see Dudeney, 1983).

With $\mu=M_{3} \sqrt{\left(0.0196 M_{3}^{2}+1\right) /\left(1.2967 M_{3}^{2}-1\right)}$, $\rho=f_{F 2} / f_{E}, \Delta=[0.253 /(\rho-1.215)]-0.012$ (if $f_{E}=0$ then $\left.\Delta=-0.012\right)$, we get $h_{m}=[(1490 \mu) /$ $\left./\left(M_{3}+\Delta\right)\right]-176 \mathrm{~km}$.

The height of the $F 1$ anchor point was originally modelled as $h_{m F 1}=\left(108.8+14 \times N_{m F 1}+\right.$ $+0.71 \times|I|) \mathrm{km}, N_{m F 1}$ being the $F 1$ peak electron density in electrons per cubic meter and $I$ being the inclination (dip) of the geomagnetic induction vector in degrees.

For the bottomside of the $F$-region, anchor point related profiling is realised by means of a sum of three semi-Epstein layers. With $N_{m F 2}=$ $=0.124 f_{F 2}^{2}, N_{m F 1}=0.124 f_{F 2}^{2}, N_{m E}=0.124 f_{E}^{2}$ being the $F 2, F 1$ and $E$-layer peak electron densities, $h_{m F 2}, h_{m F 1}, h_{m E}$ being the $F 2, F 1$ and $E$-layer peak heights, $B_{F 2}, B_{F 1}, B_{E}$ the $F 2, F 1$ and $E$-layer thickness parameters, we get for the bottom side

$$
\begin{aligned}
& N(h)=N_{F 2}(h)+N_{F 1}(h)+N_{E}(h) \\
& N_{F 2}(h)=\frac{4 N_{m F 2}}{\left[1+\exp \left(\frac{h-h_{m F 2}}{B_{F 2}}\right)\right]} \exp \left(\frac{h-h_{m F 2}}{B_{F 2}}\right) \\
& N_{F 1}(h)=\frac{4 N_{m F 1}}{\left[1+\exp \left(\zeta_{F 1}\right)\right]} \exp \left(\zeta_{F 1}\right) \\
& N_{E}(h)=\frac{4 N_{m E}}{\left[1+\exp \left(\zeta_{E}\right)\right]} \exp \left(\zeta_{E}\right)
\end{aligned}
$$

$\zeta_{L}=\frac{h-h_{m L}}{B_{L}} \exp \left(\frac{\varepsilon_{1}}{1+\varepsilon_{2} d}\right)$

with $d=\left|\left(h-h_{m F 2}\right) / B_{L}\right|, \varepsilon_{1}=10, \varepsilon_{2}=2$, index $L$ : or $F 1$, or $E$.

This modification ensures that at the $F 2$ peak the lower layers are «faded out» effectively. Examples: if $d=99$ the argument of the «fading out» exponential is 0.1 , if $d=4.5$ it is 2 , if $d=0.5$ it is 5 , if $d=0$ it is 10 .

The thickness parameters take different values for the bottomside and for the topside of the layers ( $B_{E \text { bot }}$ and $B_{E \text { top }}$ for the $E$-layer, $B_{F 1 \text { bot }}$ and $B_{F 1 \text { top }}$ for the $F 1$-layer)

$$
N_{\text {top }}(h)=\frac{4 N_{m F 2}}{[1+\exp (z)]^{2}} \exp (z)
$$

with $z=\frac{h-h_{m F 2}}{H_{O}\left[1+\frac{r g\left(h-h_{m F 2}\right)}{r H_{O}+g\left(h-h_{m F 2}\right)}\right]}$

where $H_{O}=B_{\text {top }} / v ; v=(0.041163 x-0.183981) x+$ $+1.424472 ; x=\left(B_{\text {top }}-150\right) / 100$.

The profile for the topside, too, is the upper half of an Epstein layer: $g$ is a height gradient for the scale height $H_{O},\left[r H_{O}+g\left(h-h_{m F 2}\right)\right]$ restricts the scale height increase, the factor $v$ was introduced to reduce the vertical electron content to observed values. The topside thickness parameter $B_{\text {top }}=k B_{F 2}$, with two different formulations, $k=6.705-0.014 R_{12}-0.008 h_{m F 2}$ (April to September), $k=-7.77+0.097\left(h_{m F 2} / B_{\text {top }}\right)^{2}+0.153 N_{m F 2}$ (October to March). In both cases $k$ is restricted to $2 \leq k \leq 8$.

\section{Revision of the NeQuick bottomside}

\subsection{Reason for the revision}

In «mapping» applications of NeQuick (construction of electron density grids in fixed heights below the $F 2$ peak) it became evident that in some cases strong gradients and strange structures appear in $E$ and $F 1$-layer heights (see fig. 1a). An investigation demonstrated that a large fraction of the gradient problem cases was coupled to the following behaviour of the $f_{o E}$ and $f_{o F} \mathrm{Faps}$. We found that in the critical regions and time intervals 


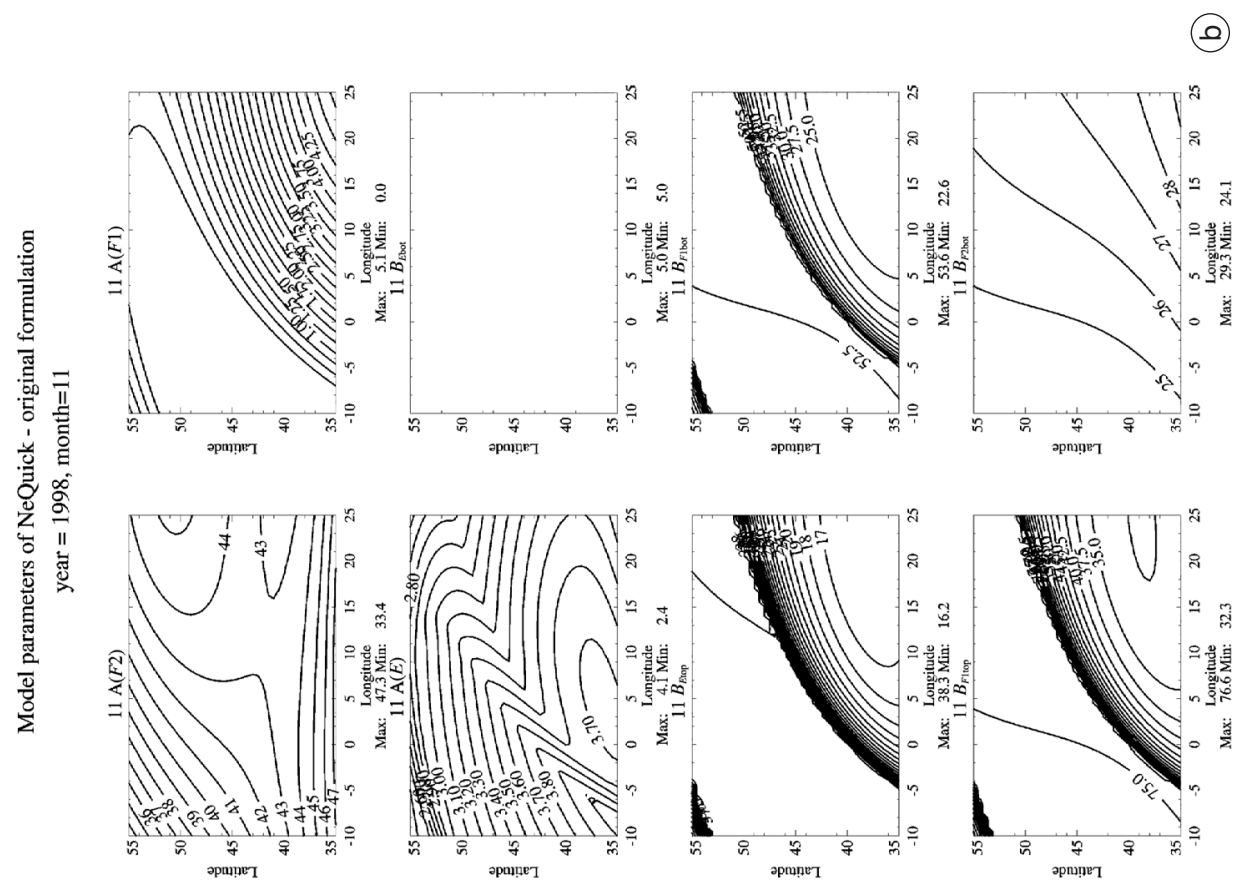

营密豈

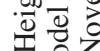

घ.

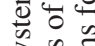

空记。

要:

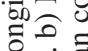

药芯

든요

글

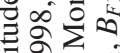

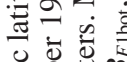

.

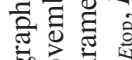

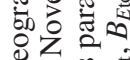

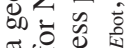

$\Xi$ 表

¿을

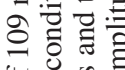

पै है चี

总䒿

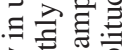

忍氞

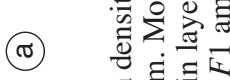

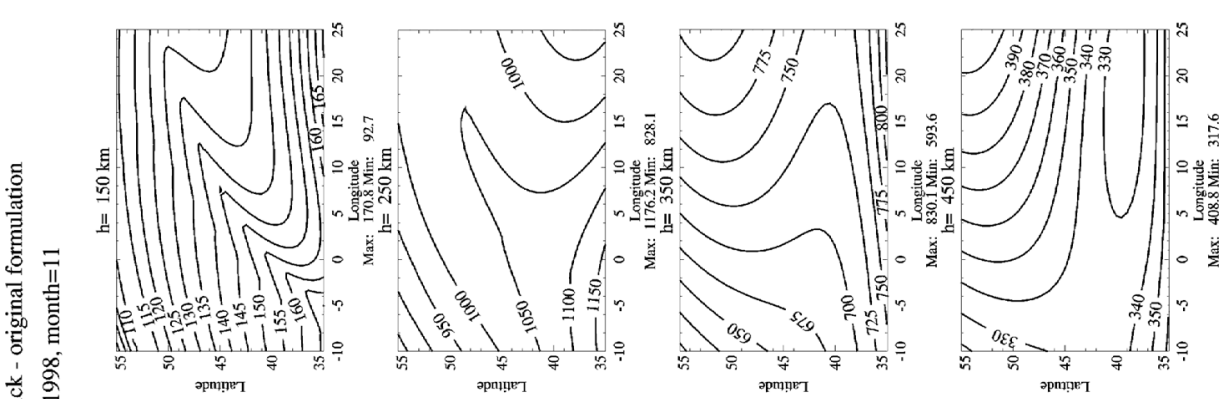

ฮ․ㅗ

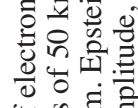
पै 苍 है

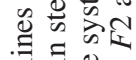

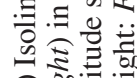
ส. 흐흔 응 을

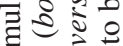
至进它
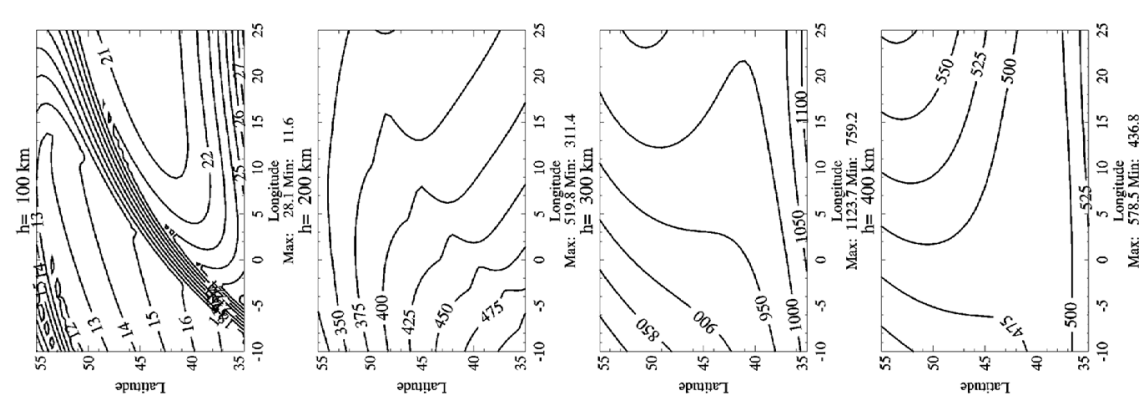

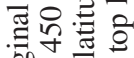
. 임을

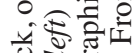
잉 언

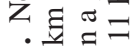
용 등 웡 볼ำ 


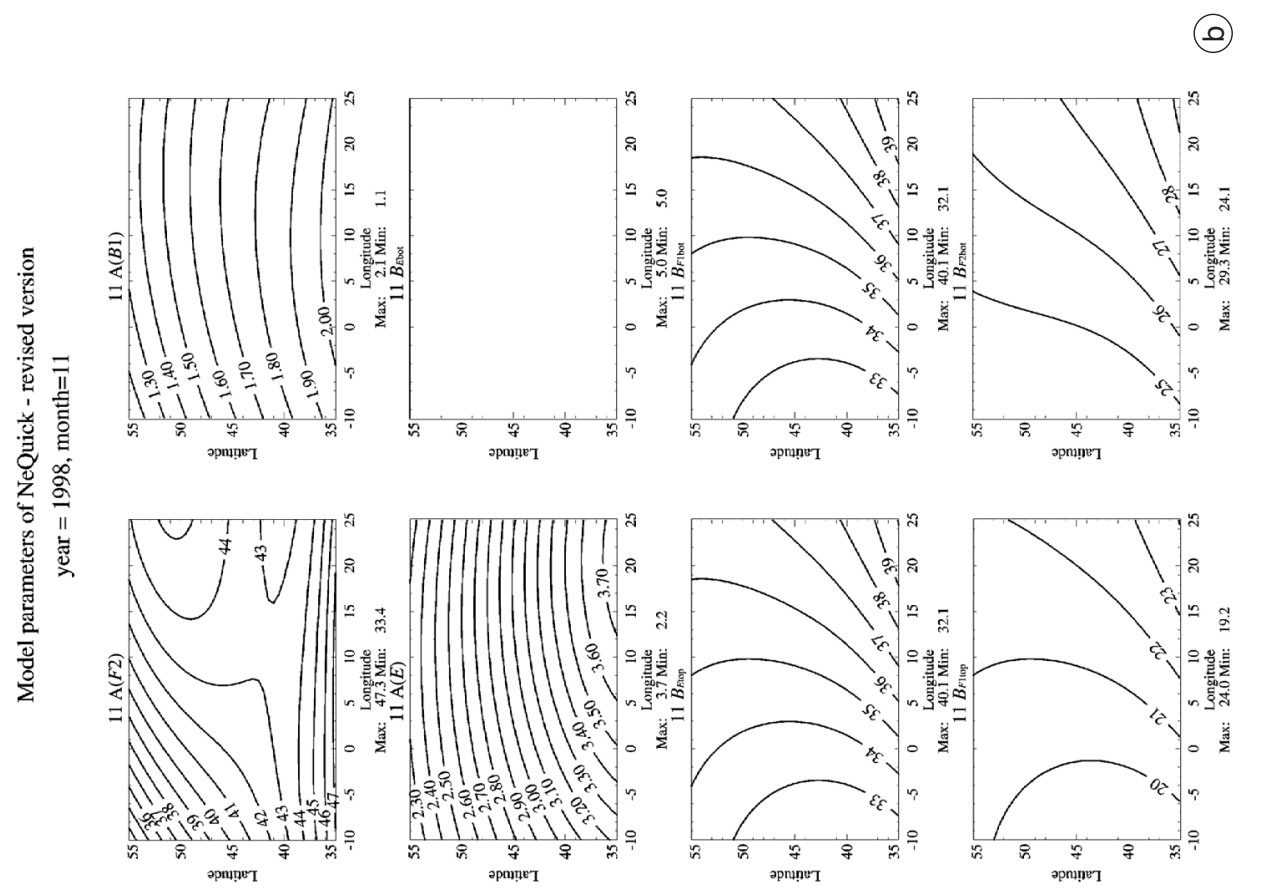

$8 \cdot \Xi=$

घै

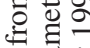

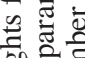

典 $\frac{2}{0}$

घ் ํํำ

क्षे

के थै

跣:

ำว

它 㠻

క

$\stackrel{2}{2}$ 근에

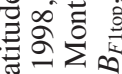

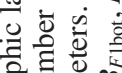

들 है है

bo

$\approx$ 它

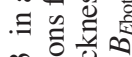

当:

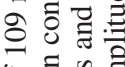

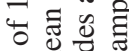

(๗) $\cong$

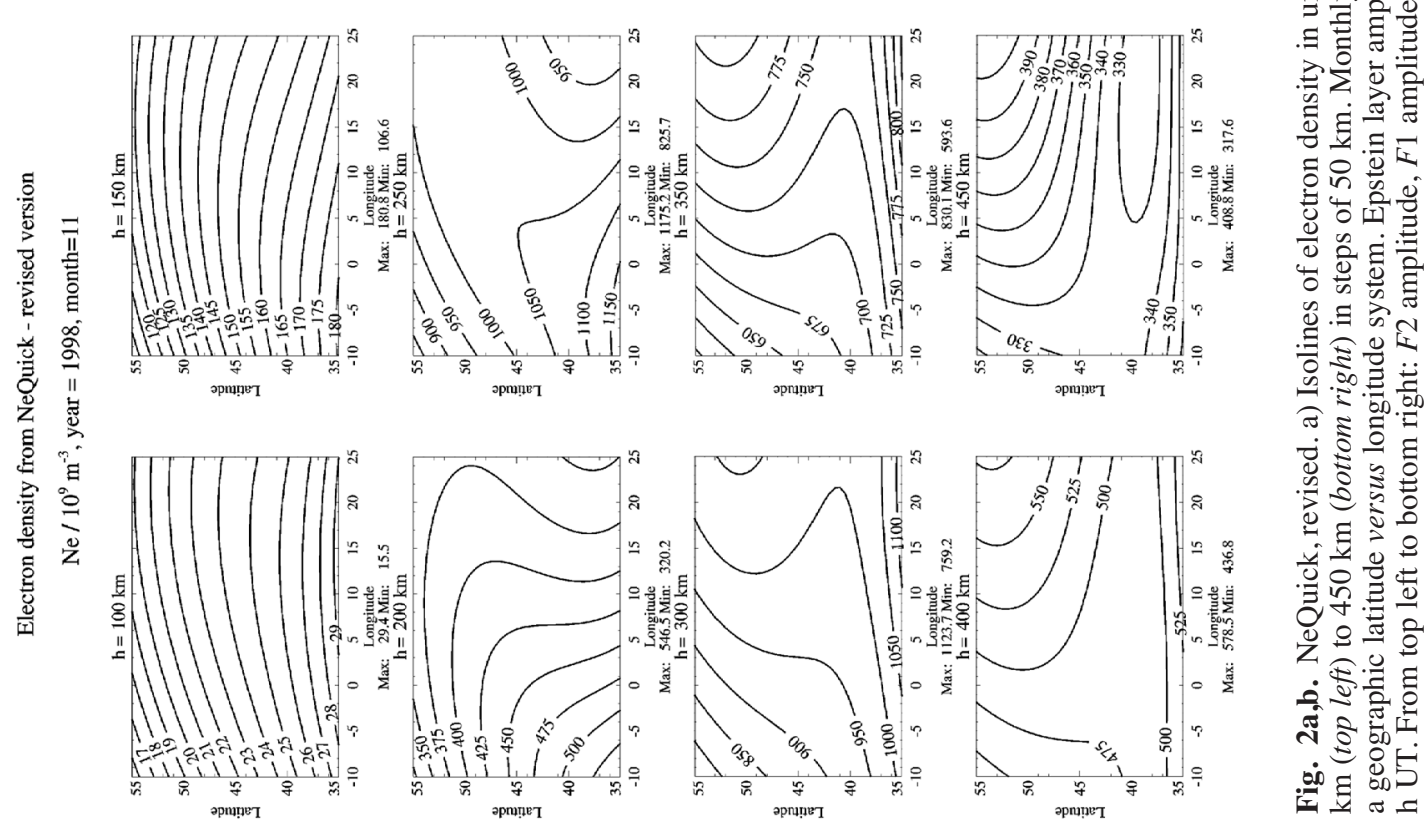


the isolines of $f o F 2$ and $f o E$ are nearly orthogonal to each other leading to difficult profile transitions. Isoline displays of electron density for constant height clearly show that the $f_{o} E$ structure (isolines nearly parallel to the abscissa) is correctly forced at the $E$-layer peak (at a height of 120 $\mathrm{km}$ ) but not above and below where the reasonable and expected structure is interrupted by strange features in the diagonal of the display (fig. 1a, isoline displays for $100 \mathrm{~km}$ and $150 \mathrm{~km}$ ). Single parameter adaptations could not solve the problem but a more elaborate revision of the original «Di Giovanni-Radicella» (DGR) modelling approach (Di Giovanni and Radicella, 1990; Radicella and Zhang, 1995) was necessary.
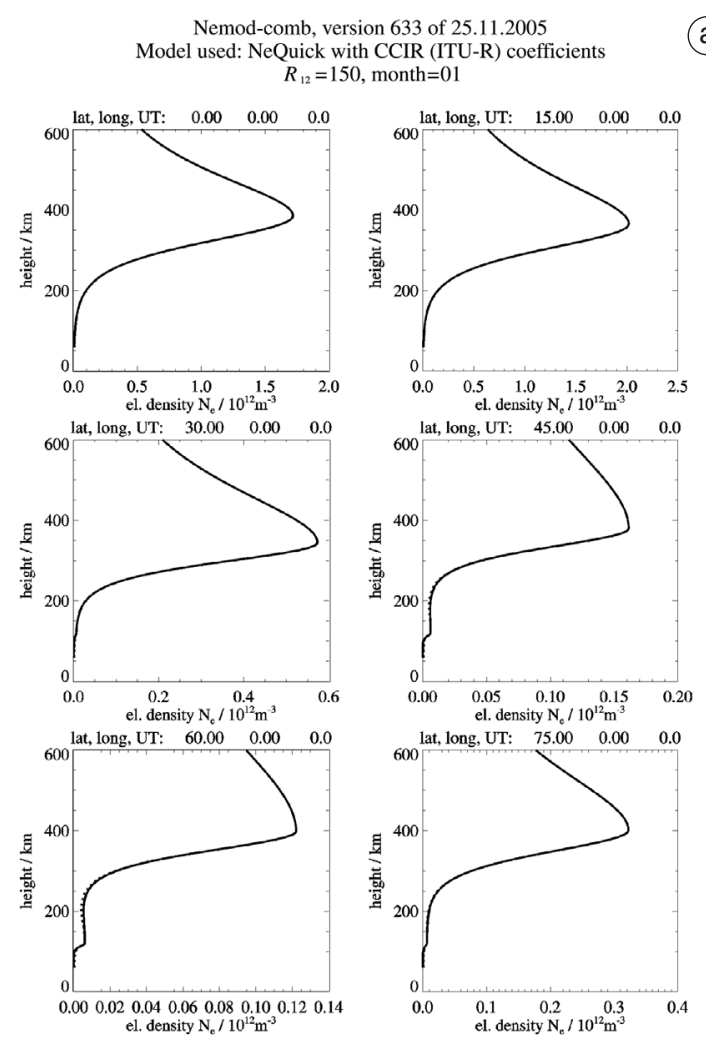

\subsection{The most important revisions}

Following an elaborate parameter adaptation strategy and after many tests we adopted the revisions:

1) Replace the formerly complicated formulation for the height of the $F 1$ peak, $h_{m F 1}$, by using $h_{m F 1}=\left(h_{m F 2}+h_{m E}\right) / 2$.

2) Set $f o F 1$ to zero if $f o E$ is smaller than 2 $\mathrm{MHz}$ and avoid that $f_{o} F 1$ gets too close to $f o F 2$. The original formulation was $f_{F 1}=1.4 f_{E}$ under all daytime conditions. Now $f_{F 1}=0.85 \times 1.4 f_{E}$ if $1.4 f_{E}>0.85 f_{F 2}$.

3) Introduce simplified formulations for the thickness parameters $B_{F 1 \text { top }}, B_{F 1 \text { bot }}$ and $B_{E \text { top }}$.

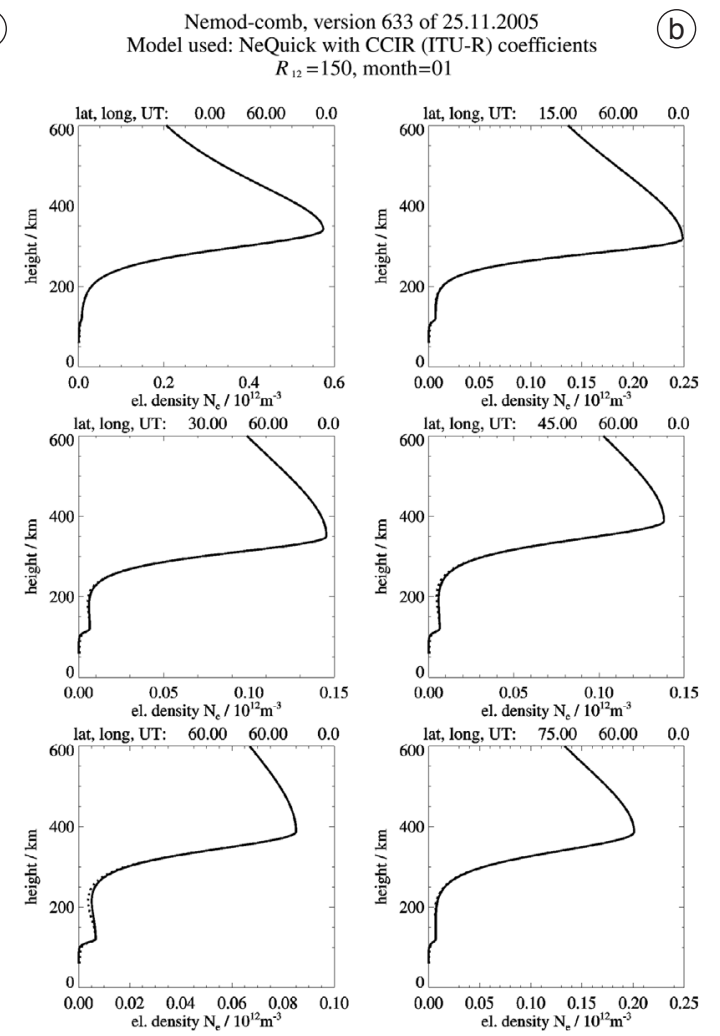

Fig. 3a,b. Height profiles of electron density: January; $R_{12}=150 ; 0$ h UT; geografic longitude $0^{\circ} \mathrm{E}(\mathrm{a}), 60^{\circ} \mathrm{E}$ (b); $0 \mathrm{~h} \mathrm{LT}$ (a), $4 \mathrm{~h} \mathrm{LT} \mathrm{(b);} \mathrm{geografic} \mathrm{latitudes} 0^{\circ} \mathrm{N}$ (top left) to $75^{\circ} \mathrm{N}$ (bottom right), latitude spacing $15^{\circ}$. Solid curves: revised NeQuick, dotted curves: NeQuick, old formulation. 
Nemod-comb, version 633 of 25.11.2005 Model used: NeQuick with CCIR (ITU-R) coefficients $R_{12}=150$, month $=01$
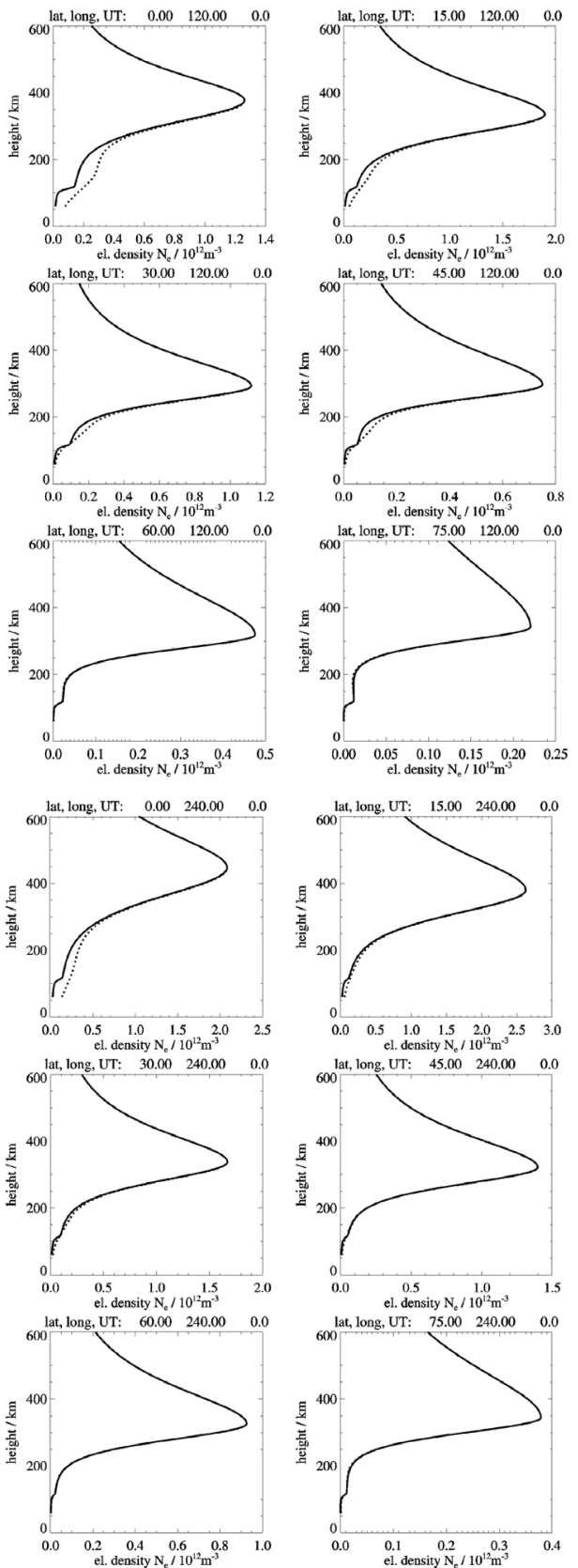

(C) $R_{12}=150$, month $=01$
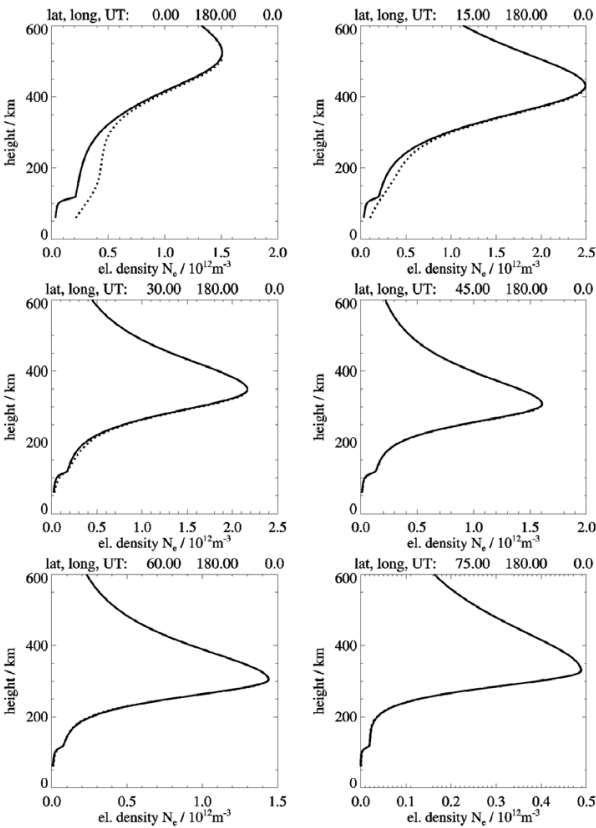

(e)
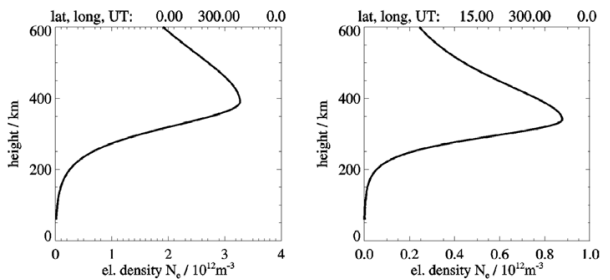
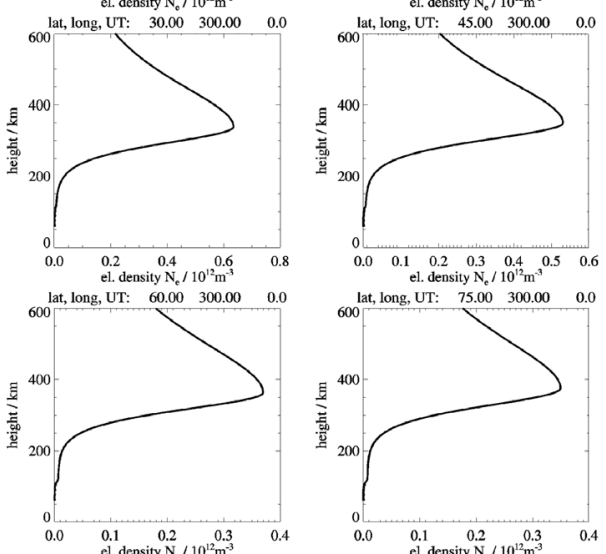

(d) 
The complete set of thickness parameters now is $B_{F 2}=38.5 N_{m F 2} / d$ with $d=\exp [(-3.467+0.857$. $\left.\cdot \ln \left(f_{F 2}^{2}\right)+2.02 \ln \left(M_{3}\right)\right] ; \quad B_{F 1 \text { top }}=0.3\left(h_{m F 2}-h_{m F 1}\right)$; $B_{F 1 \mathrm{bot}}=0.5\left(h_{m F 1}-h_{m E}\right) ; B_{E \mathrm{top}}=0.5\left(h_{m F 1}-h_{m E}\right)$ or $B_{E \text { top }}=7$ whatever is larger; $B_{E \text { bot }}=5$.

\section{Comparison of NeQuick-ITUR with the revised NeQuick}

The following collection of maps and profiles demonstrates the improvement of the NeQuick properties.

The comparison of fig. 2a (revised NeQuick) with fig. 1a (NeQuick before revision) clearly shows that strong gradients and strange structures have disappeared. This is especially true for $E$ layer heights and for the $E-F 1$ transition region. Figure $1 \mathrm{~b}$ connects the strong gradients and strange structures to the latitude-longitude distribution of $E$ and $F 1$ thickness parameters $B_{E \text { top }}$, $B_{F 1 \text { bot }}$ and $B_{F 1 \text { top }}$ and to the amplitude of the $E$-Epstein layer, $A(E)$. Figure $2 \mathrm{~b}$ shows that after the revision all these parameters are very well behaved.

The profile comparisons of fig. 3a-f (January, high solar activity) and fig. 4a-f (April, low solar activity) show that two profile peculiarities have disappeared with the revision:

a) A low latitude «contamination» of the $E$ layer by the $F 1$-layer leading to electron densi-

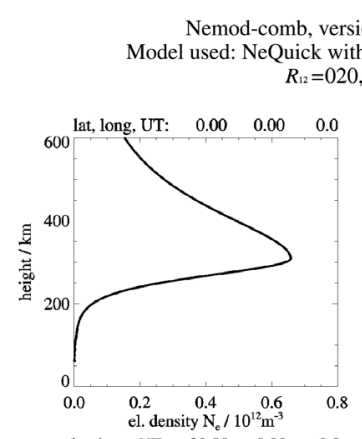

Nemod-comb, version 633 of 25.11.2005 Model used: NeQuick with CCIR (ITU-R) coefficients

(b) $R_{12}=020$, month $=04$
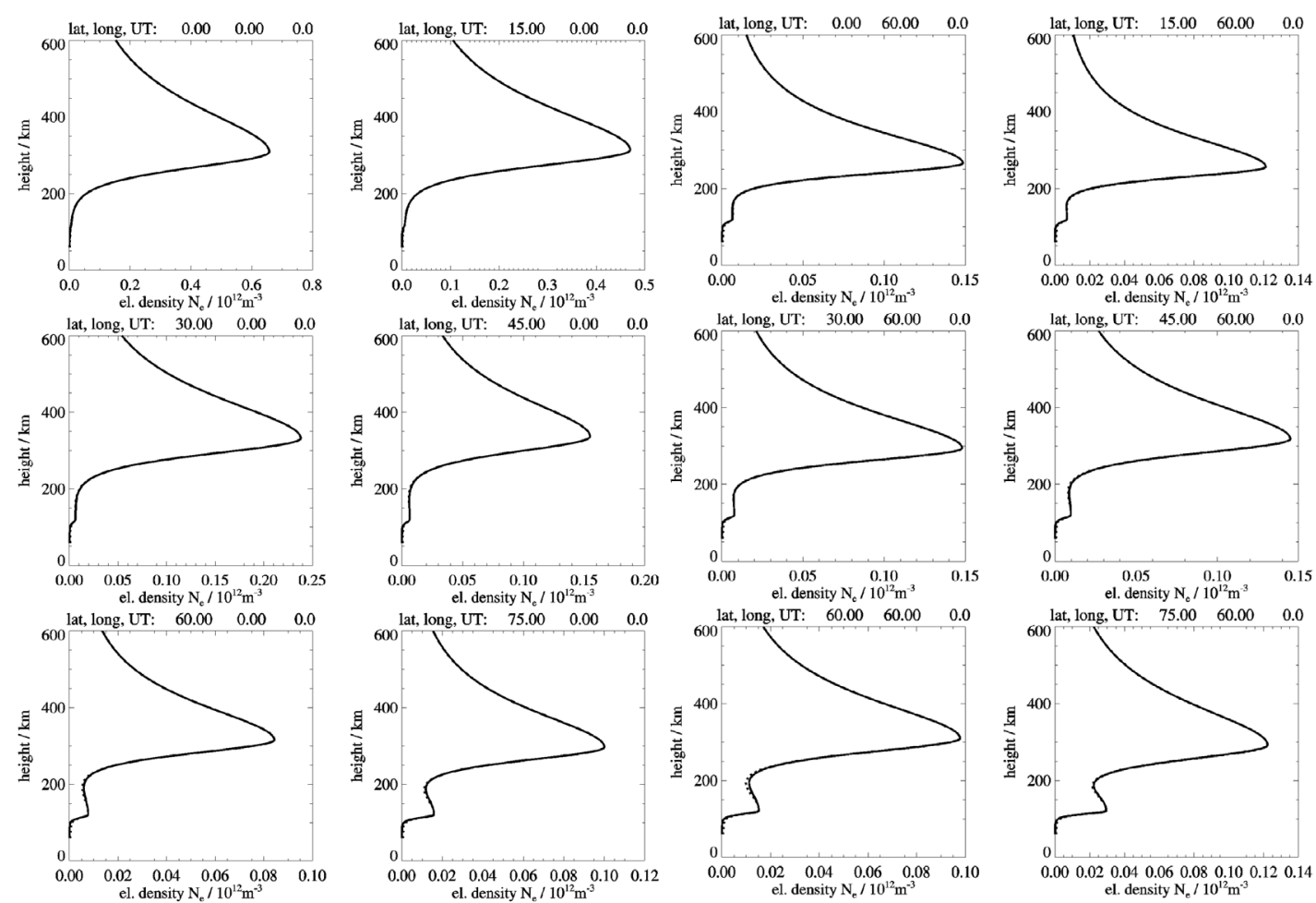

Fig. 4a,b. Height profiles of electron density: April; $R_{12}=20 ; 0$ h UT; geografic longitude $0^{\circ} \mathrm{E}(\mathrm{a}), 60^{\circ} \mathrm{E}$ (b); 0 $\mathrm{h}$ LT (a), 4 h LT (b); geografic latitudes $0^{\circ} \mathrm{N}$ (top left) to $75^{\circ} \mathrm{N}$ (bottom right); latitude spacing $15^{\circ}$. Solid curves: revised $\mathrm{NeQuick}$, dotted curves: NeQuick, old formulation. 
Nemod-comb, version 633 of 25.11 .2005

Model used: NeQuick with CCIR (ITU-R) coefficients

$$
R_{12}=020, \text { month }=04
$$
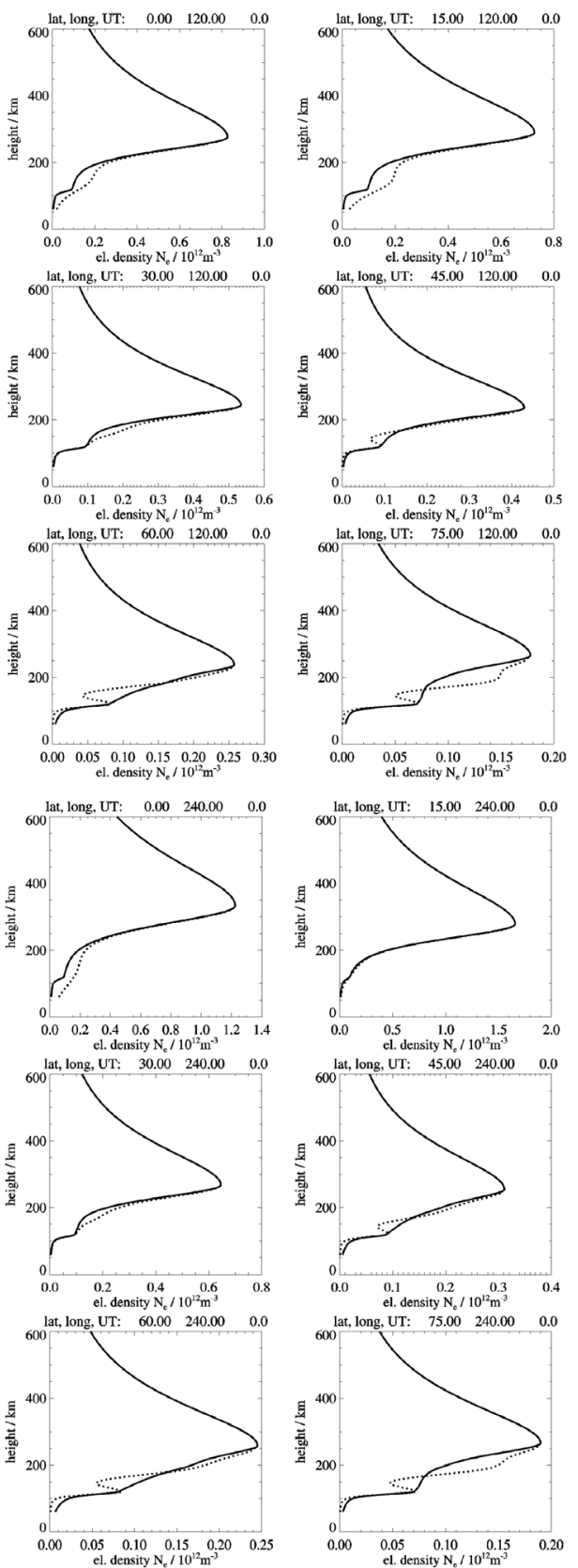

(e)
Nemod-comb, version 633 of 25.11 .2005

Model used: NeQuick with CCIR (ITU-R) coefficients $R_{12}=020$, month $=04$
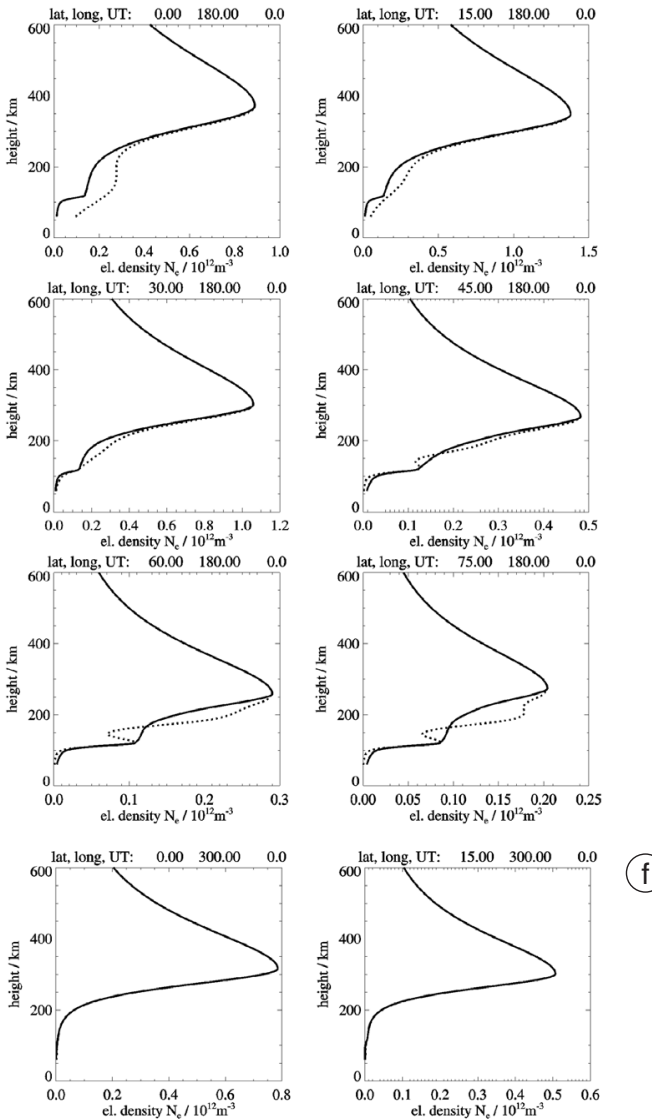

(f)
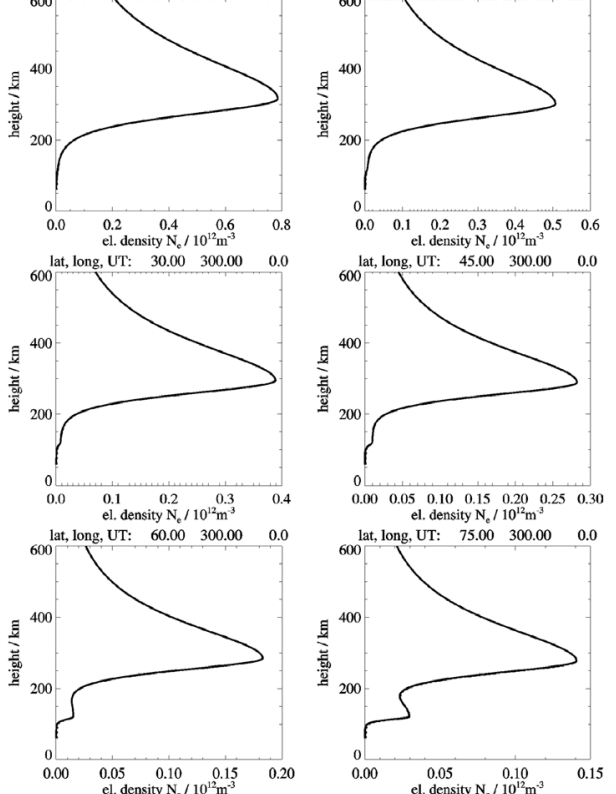

Fig. 4c-f. Height profiles of electron density: April; $R_{12}=20 ; 0 \mathrm{~h} \mathrm{UT}$; geografic longitude $120^{\circ} \mathrm{E}(\mathrm{c}), 180^{\circ} \mathrm{E}$ (d), $240^{\circ} \mathrm{E}$ (e), $300^{\circ} \mathrm{E}$ (f); $8 \mathrm{~h} \mathrm{LT}$ (c), $12 \mathrm{~h} \mathrm{LT} \mathrm{(d),} 16 \mathrm{~h} \mathrm{LT} \mathrm{(e),} 20 \mathrm{~h} \mathrm{LT} \mathrm{(f);} \mathrm{geografic} \mathrm{latitudes} 0^{\circ} \mathrm{N}$ (top left) to $75^{\circ} \mathrm{N}$ (bottom right); latitude spacing $15^{\circ}$. Solid curves: revised NeQuick, dotted curves: NeQuick, old formulation. 
Nemod-comb, version 633 of 25.11 .2005 Model used: NeQuick with CCIR (ITU-R) coefficients $R_{12}=150$, month $=07$
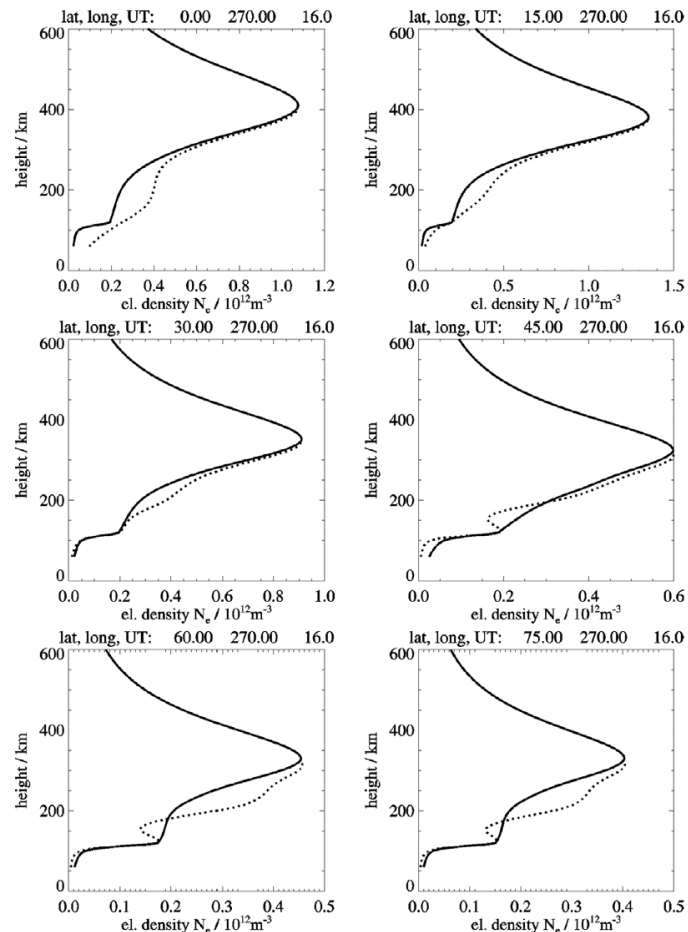

Fig. 5. Height profiles of electron density: July; $R_{12}=150 ; 16 \mathrm{~h} \mathrm{UT}$; geografic longitude $270^{\circ} \mathrm{E} ; 10 \mathrm{~h}$ LT; geografic latitudes $0^{\circ} \mathrm{N}$ (top left) to $75^{\circ} \mathrm{N}$ (bottom right); latitude spacing $15^{\circ}$. Solid curves: revised NeQuick, dotted curves: NeQuick, old formulation.

ties larger than $N m(E)$ at the presumed $E$-layer peak of $120 \mathrm{~km}$ (top rows of fig. 4c,d).

b) A (upper mid and) high latitude «contamination» of the $F 2$-layer by the $F 1$-layer leading to secondary maxima somewhere between the $F 1$ and the $F 2$ peaks (figs. 5 and 6 ). In some cases the secondary maxima had electron density values larger than $N m(F 2)$ (e.g., bottom of fig. $5)$. These artifacts tended to appear in the «old» NeQuick around $10 \mathrm{~h}$ Local Time (LT) both under high solar activity conditions (fig. 5) and low solar activity conditions (fig. 6).

The revised NeQuick has been released on 25 November, 2002 after automatic checking of
Nemod-comb, version 633 of 25.11 .2005 Model used: NeQuick with CCIR (ITU-R) coefficients $R_{12}=020$, month $=04$
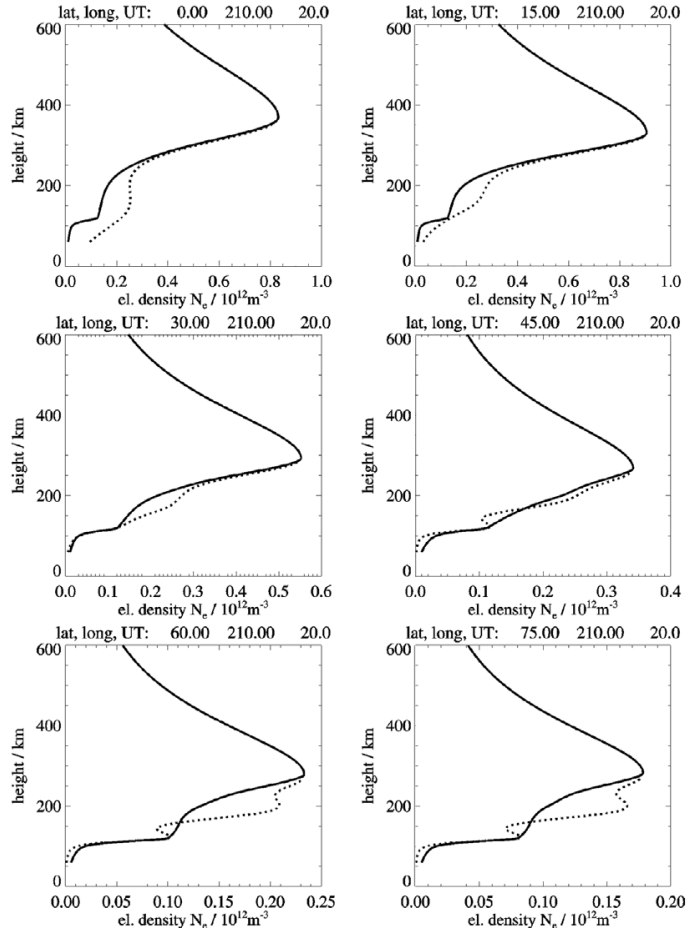

Fig. 6. Height profiles of electron density: April; $R_{12}=20 ; 20$ h UT; geografic longitude $210^{\circ} \mathrm{E} ; 10 \mathrm{~h}$ LT; geografic latitudes $0^{\circ} \mathrm{N}$ (top left) to $75^{\circ} \mathrm{N}$ (bottom right); latitude spacing $15^{\circ}$. Solid curves: revised NeQuick, dotted curves: NeQuick, old formulation.

about 72000 and systematic visual inspection of hundreds of model profiles gained in all seasons under high, mid and low solar activity conditions and distributed globally in latitude and longitude and distributed over Universal Time (UT) days.

\section{REFERENCES}

BradLey, P.A. and J.R. Dudeney (1973): A simple model of the vertical distribution of electron concentration in the ionosphere, J. Atmos. Terr. Phys., 35, 2131-2146.

Di GiovanNi, G. and S.M. Radicella (1990): An analytical model of the electron density profile in the ionosphere, Adv. Space Res., 10, 27-30. 
DuDENEY, J.R. (1983): The accuracy of simple methods for determining the height of the maximum electron concentration of the F2-layer from scaled ionospheric characteristics, J. Atmos. Terr. Phys., 45, 629-640.

ITU-R (1997): Reference ionosphere characteristics, Recommendation P.1239 (approved in 1997-05, managed by ITU-R Study Group SG3).

Leitinger, R., J.E. Titheridge, G. Kirchengast and W. RothleITNER (1995): A «simple» global empirical model for the $F$-layer of the ionosphere, Wiss. Bericht 1/1995, IMG Universität Graz.

Leitinger, R., J.E. Titheridge, G. Kirchengast and W. RothlEITNER (1996): Ein «einfaches» globales empirisches Modell für die $F$-Schicht der Ionosphäre, Kleinheubacher Berichte, 39, 697-704.
Leitinger, R., S.M. Radicella, B. Nava, G. HochegGer and J. HAFNER (1999): NeQuick - COSTprof - NeUoGplas, a family of 3D electron density models, in Proceedings of the COST251 Madeira Workshop, 75-89.

RADiCELLA, S.M. and R. LEITINGEr (2001): The evolution of the DGR approach to model electron density profiles, Adv. Space Res., 27, 35-40.

Radicella, S.M. and M.L. Zhang (1995): The improved DGR analytical model of electron density height profile and total electron content in the ionosphere, Ann. Geofis., XXXVIII (1), 35-41.

RAwER, K. (1963): Propagation of decameter waves (HF band), in Meteorological and Astronomical Influences on Radio Wave Propagation, edited by B. LANDMARK (New York Academic Press), 221-250. 